\title{
Azorín y la "historia menuda" de España: una lectura de Los pueblos (1905)
}

\author{
Azorín and the "historia menuda" of Spain: a Reading of Los pueblos \\ (1905)
}

\author{
Francisco Fuster García \\ francisco.fuster@cchs.csic.es \\ Doctor \\ Instituto de Lengua, Literatura y Antropología (CCHS-CSIC) \\ C/Albasanz, 26-2828037 - Madrid \\ España
}

\section{Resumen}

El propósito de este trabajo es proponer una lectura de Los pueblos (1905) desde el punto de vista del historiador; concretamente, desde la perspectiva de dos corrientes historiográficas -la microhistoria y la history from below - surgidas en Europa durante los años setenta con el objetivo fundamental de recuperar al individuo anónimo como sujeto histórico, prestando atención a las "clases subalternas" de la sociedad. Mediante el análisis de dicha obra, mi intención es demostrar que la concepción que tiene Azorín de la historia de España responde a una idea fundamental: la necesidad de conceder la atención que merecen a los pequeños hechos y sucesos de la vida cotidiana protagonizados por individuos anónimos que no forman parte de la historia.

\section{Palabras clave}

Microhistoria; Historicidad; Literatura.

\begin{abstract}
The aim of this paper is to propose a reading of Los pueblos (1905) from the point of view of the historian, specifically from the perspective of two historiographical trends - microhistory and history from below -, which emerged in Europe during the 1970s with the fundamental objective of reinstating the anonymous individual as a historical subject, paying attention to the "subaltern classes" of society. By analyzing this work, my intention is to show that Azorin's conception of the history of Spain meets a fundamental idea: the need to give due attention to small events and episodes of everyday life featuring anonymous individuals who are not recognized as part of history.
\end{abstract}

\section{Keywords}

Micro-history; Historicity; Literature.

Recibido el: 17/11/2013

Aprobado el: 10/3/2014 
Juan Luis Vives ha sentido acaso mejor que nadie la eterna poesía de lo pequeño y cotidiano. $Y$ he aquí por qué, entre toda su obra, tal vez viene a prevalecer y dominar, como siempre acontece, aquello que el autor reputó por más frívolo, pero en que llegó, inconscientemente, por vías indirectas, hasta el nexo secreto de la vida. Hablo de los Diálogos que el gran filósofo escribió para ejercicio de la lengua latina: acaso no hay libro en nuestra literatura tan íntimo y gustoso. Abridlo: ved cómo pasa la existencia menuda y prosaica de los pueblos en una serie de pequeños cuadros auténticos...

José Martínez Ruiz. Filósofos españoles: Vives. Los Lunes de El Imparcial, 23 nov. 1903.

\section{Una filosofía azoriniana de la historia}

En un excelente ensayo de interpretación escrito en 1913 bajo el revelador título de "Azorín o primores de lo vulgar", José Ortega y Gasset llegaba a la conclusión de que existía en la producción literaria de Azorín ${ }^{1}$ un rasgo que la caracterizaba más que ningún otro. Para el filósofo madrileño, aquello que diferenciaba a este escritor del resto era su especial habilidad para fijarse en esos pequeños detalles que pasan inadvertidos en la vorágine del día a día:

En Azorín no hay nada solemne, majestuoso, altisonante. Su arte se insinúa hasta aquel estrato profundo de nuestro ánimo donde habitan estas menudas emociones tornasoladas. No le interesan las grandes líneas que, mirada la trayectoria del hombre en sintética visión, se desarrollan serenas, simples y magníficas, como el perfil de una serranía. Es todo lo contrario de un "filósofo de la historia". Por una genial inversión de la perspectiva, lo minúsculo, lo atómico, ocupa el primer rango en su panorama, y lo grande, lo monumental, queda reducido a un breve ornamento (ORTEGA Y GASSET 2004, p. 293).

Desde el punto de vista de lo que podríamos llamar su "filosofía de la historia", su forma de entender lo que es -y lo que debería ser- la historia, la predilección por la "eterna poesía de lo pequeño y cotidiano", que nuestro autor decía haber aprendido en los Diálogos de Vives, se materializa en una doble fijación: su interés por lo que él mismo denominaba "pequeños hechos" y, ligado a ese interés, su atracción por las "vidas opacas" de aquellos individuos anónimos que viven al margen de la "historia oficial".

Por lo que se refiere a la primera de esas dos preocupaciones, resulta sintomático el hecho de que hace ya más de cuatro décadas - cuando todavía no existía la microstoria italiana como corriente historiográfica-, José Antonio Maravall defendió en un pionero estudio que, por el énfasis puesto en "esos hechos pequeños en su aparente figura externa, que hacen tan lento el ritmo del tiempo" (MARAVALL 1968, p. 51), la idea azoriniana de la historia podría responder bien

\footnotetext{
1 José Augusto Trinidad Martínez Ruiz (Monóvar, Alicante, 1873 - Madrid, 1967), más conocido por el pseudónimo de "Azorín", fue un destacado escritor y periodista español que formó parte de la llamada "Generación del 98". Ejerció el periodismo y la crítica literaria durante siete décadas - publicó alrededor de cinco mil artículos entre 1895 y $1965-$ y colaboró en algunos de los periódicos españoles más importantes de la primera mitad del siglo XX (ABC, El Imparcial, La Vanguardia, etc.), así como en el diario argentino La Prensa, de Buenos Aires. Entre los géneros literarios que cultivó destacan la novela, el ensayo, el teatro y las memorias. Aunque en su juventud fue anarquista y regeneracionista, a partir de 1905, y coincidiendo con su llegada al periódico $A B C$, adoptó un ideario conservador que mantuvo durante el resto de su vida e, incluso, llegó a participar en la política española siendo varias veces diputado en las Cortes representando al Partido Conservador.
} 
al nombre de "microhistoria". Sin embargo, y por tratar de ayudar en lo posible al lector menos familiarizado con el vocabulario de la disciplina histórica, conviene precisar que la petite histoire a la que se refiere Azorín en varias ocasiones y la "microhistoria" en el sentido actual de la palabra no son estrictamente la misma cosa. Cuando Azorín habla de la petite histoire o de la "historia menuda" en alguna de sus habituales - pero muy poco conocidas- reflexiones sobre la historia, se refiere sobre todo a lo que la historiografía moderna llamaría "historia local": la historia limitada a un espacio geográfico reducido y a un período de tiempo acotado. Aunque es verdad que en esto el enfoque de Azorín coincide con el método microhistórico, lo cierto es que la microhistoria es una modalidad de la historia distinta, en sus objetivos y métodos, de la historia local propiamente dicha. Como sabemos, la microhistoria es una propuesta metodológica que se caracteriza fundamentalmente por proponer una reducción en la escala de análisis del historiador, que pasa de fijarse en las masas sociales o los grandes acontecimientos históricos a tomar lo particular (lo específico e individual, no lo típico) como objeto de estudio para tratar de entenderlo y situarlo en su contexto. La aplicación de ese método de análisis dio lugar a una corriente historiográfica homónima - nacida en Italia y desarrollada en el resto de Europa a partir de la década de los años setenta- que tiene su punto de partida en la publicación de la obra del historiador italiano Carlo Ginzburg, El queso y los gusanos (1976).

Junto con esa capacidad de observación y esa voluntad de captar lo minúsculo, la otra gran característica de la aproximación azoriniana al pasado es el hechizo que ejercen sobre el escritor las vidas aparentemente irrelevantes de esos personajes que conforman la masa anónima de la historia. Como explicó Ortega, "Azorín ve en la historia no grandes hazañas ni grandes hombres, sino un hormiguero solícito de criaturas anónimas que tejen incesantemente la textura de la vida social, como las células calladamente reconstruyen los tejidos orgánicos" (ORTEGA Y GASSET 2004, p. 317). Es a esas existencias modestas que tanto le atraían a las que se refería nuestro autor en un capítulo de Las confesiones de un pequeño filósofo titulado "Las vidas opacas":

Yo no he ambicionado nunca, como otros muchachos, ser general u obispo; mi tormento ha sido $-\mathrm{y}$ es - no tener un alma multiforme y ubicua para poder vivir muchas vidas vulgares e ignoradas; es decir, no poder meterme en el espíritu de este pequeño regatón que está en su tiendecilla oscura; de este oficinista que copia todo el día expedientes y por la noche van él y su mujer a casa de un compañero, y allí hablan de cosas insignificantes; de este saltimbanqui que corre por los pueblos; de este hombre anodino que no sabemos lo que es ni de qué vive y que nos ha hablado una vez en una estación o en un café [...] (AZORÍN 1990, p. 118).

En ese interés por las "clases subalternas" de la historia, Azorín se adelanta en varias décadas a otra corriente historiográfica surgida en Inglaterra durante los años sesenta: la llamada "historia desde abajo" o history from below; esto es, la historia que -como su propio nombre lo indica- quiere rescatar el protagonismo de las clases populares o trabajadoras que ocupan los estratos más bajos de la sociedad. Como sucede con la microhistoria, al 
señalar esa coincidencia de enfoques no estoy queriendo decir que el escritor alicantino practicara la historia desde abajo; primeramente, porque todavía no existía como tal y, en segundo lugar, porque Azorín no fue ni quiso ser nunca historiador. Lo que pretendo hacer ver al lector es que existe una confluencia entre los motivos de interés de nuestro autor y los que, años más tarde, serán objetos de estudio de dos tendencias historiográficas surgidas muchas décadas después. En el caso concreto de la historia desde abajo, son varios los textos en los que Azorín advierte en el discurso hegemónico ese sesgo sobre el pasado que excluía las referidas clases y denuncia, a su manera, la invisibilidad de quienes no formaban parte de la historia:

Las catedrales y los palacios son grandes y ostentosos; los nombres de quienes han levantado las catedrales y de quienes han morado en los palacios, tal vez han pasado a la Historia. Pero en estas casas humildes, a lo largo de los siglos, han vivido generaciones de gentes que han trabajado y sufrido en silencio. Y estas paredes blancas y estas maderas ahumadas, anodinas, sin primores artísticos, vulgares, llegan acaso a producir una emoción más honda, más inefable que los maravillosos monumentos (AZORÍN 1957, p. 72-73).

Lo que a continuación pretendo explicar es cómo se materializa la teoría en la práctica y cómo se plasma esa personal manera de entender la historia -y en particular la historia de España- en Los pueblos, un título fundamental para entender no solo la filosofía azoriniana de la historia, sino el conjunto de la obra de un escritor cuya estética se consolida de forma definitiva a raíz, precisamente, de la aparición de dicho libro.

\section{Vindicación de la "historia menuda": a propósito de Los pueblos}

Los pueblos se publicó por primera vez a principios de 1905, en la colección "Biblioteca Nacional y Extranjera", reuniendo un total de 18 artículos aparecidos con anterioridad -entre abril y noviembre de 1904- en el periódico España, seleccionados y ordenados por el propio Azorín. Como prueba del éxito fulgurante del libro, ese mismo año, y en el mismo sello del editor inglés Leonardo Williams, el volumen fue reeditado por primera vez, respetando su contenido original. Fue con ocasión de su tercera edición (Renacimiento, 1914) que la obra sufrió su primera modificación, al incorporarse los cinco artículos publicados por Azorín en El Imparcial bajo el epígrafe de "La Andalucía trágica". Cuando aparecieron las Obras Selectas de nuestro autor (Biblioteca Nueva, 1943), el responsable de la edición, Ángel Cruz Rueda, añadió al contenido de esa tercera edición dos nuevos textos aparecidos en España: "La muerte de un amigo: Sarrió" (20 enero 1905) y "Confesión de un autor" (6 feb 1905). Esta edición es la que se recogió en las Obras Completas de Azorín publicadas por Aguilar a finales de los años cuarenta y la que se suele seguir en las ediciones más recientes de la obra, aunque en este trabajo voy a usar la versión de Los pueblos incluida en el volumen II de las Obras escogidas de Azorín coordinadas por Miguel Ángel Lozano Marco, donde se reproduce la primera edición del libro y se incluyen en un apéndice final los textos que se fueron añadiendo en esas ediciones posteriores. 
Dejando al margen ahora las reediciones, quiero reparar en la primera de 1905 por la importancia que reviste su aparición en esa fecha concreta, pues se trata del momento decisivo en el que José Martínez Ruiz abandona definitivamente tanto los seudónimos que había utilizado en su juventud, como su nombre de pila, y pasa a firmar sus colaboraciones en la prensa y sus libros con el seudónimo de "Azorín". Como se ha encargado de señalar la crítica, la adopción de esa firma no será un simple cambio de nombre, sino toda una declaración de principios que lleva implícita y representa, además, el inicio de una nueva etapa en la trayectoria azoriniana. En ese sentido, coincido con Ramón Jiménez en que Los pueblos - primer libro que Azorín firma con ese seudónimo- es una "obra gozne" que "sella la época de juventud del artista y da paso a otra, mucho más serena, al margen de los pujos anarquistas e ímpetus reformistas que le acompañaron en su juventud" (JIMÉNEZ MADRID 2002, p. 13); o, en palabras de José María Valverde, "si La voluntad fue la mejor obra de J. Martínez Ruiz, Los pueblos es la mejor obra de Azorín" (VALVERDE 1974, p. 26). Como ha señalado Miguel Ángel Lozano Marco, esa obra marca una especie de transición estética entre novelas como Antonio Azorín (1903) o Las confesiones de un pequeño filósofo (1904), donde ya encontramos prefigurados algunos temas presentes en Los pueblos, y los libros que le seguirán - La ruta de Don Quijote (1905), España. Hombres y paisajes (1909) y Castilla (1912)—, que forman una especie de ciclo inaugurado precisamente con este volumen de 1905 (LOZANO MARCO 1998, p. 38-39).

Desde el punto de vista de su estructura interna, Los pueblos está compuesto por dieciocho capítulos -estampas o cuadros- de naturaleza heterogénea (cuentos, ensayos, poemas en prosa, etc.) que, sin embargo, comparten un mismo hilo conductor: la existencia aparentemente tranquila y vulgar en esos pueblos de la España rural y provinciana de principios del siglo XX. Y es justamente ese deseo de Azorín de retratar la "historia menuda" de los hombres y las mujeres en su vida cotidiana lo que me interesa destacar en mi lectura. Ante la imposibilidad de realizar un análisis pormenorizado de cada uno de esos cuadros, destacaré unos pocos pasajes de la obra en los que creo que se resume bien esa filosofía azoriniana de la historia que he tratado de sintetizar en la introducción.

Tanto el capítulo titulado "Sarrió" como el artículo "La muerte de un amigo: Sarrió", que es continuación del anterior y que fue añadido a Los pueblos en 1943, constituyen, a mi juicio, una buena muestra de esa atracción de nuestro autor por esos individuos anónimos a la que ya me he referido. Se trata de dos textos en los que el protagonista de Los pueblos - que en la mayoría de capítulos es el propio Azorín - narra su encuentro con un viejo amigo ciego que, ya al final de su vida, regresa a su pueblo después de una temporada fuera para morir en paz entre los recuerdos del pasado y rodeado por los suyos. El caso de Sarrió se nos presenta como el de "uno de estos hombres, de estos artistas maravillosos que viven y se extinguen sin que el mundo se percate de su existencia" (AZORÍN 1998, p. 1606). Recordando, quizá, su propia experiencia autobiográfica en los pueblos alicantinos de Monóvar y Petrer, donde pasó buena parte de su 
infancia, Azorín ve en los vecinos de Sarrió ejemplos de esas "vidas opacas" que parecen no interesar a los historiadores de su tiempo y que, sin embargo, también son, a su manera, héroes: "hay en los pueblos hombres y mujeres, vulgares, anodinos, insignificantes, que os han encantado con su afabilidad, con sus palabras sencillas, y cuya desaparición os causa tanto pesar como la de un héroe o la de un gran artista" (AZORÍN 1998b, p. 309).

En "Una elegía", esa mirada sobre las clases trabajadoras se centra en el mundo de esos oficios antiguos de pueblo que se mantienen a lo largo de los siglos pasando de generación a generación. Por medio de lo que puede parecer una reflexión sobre un tema muy concreto, Azorín nos da su personal opinión sobre el secular conflicto entre tradición y modernidad, oponiendo el trabajo industrial de la civilización urbana al trabajo artesanal de los pueblos de España en los que todavía se conserva la tradición:

Yo pienso que todas estas cerraduras, estos pasadores, estas fallebas, fabricadas en grande, mecánicamente, en los enormes talleres cosmopolitas, entre la multitud rápida y atronadora de los obreros, no tienen alma, no tienen ese algo misterioso e indefinible de las piezas forjadas en las viejas edades, que todavía en los pueblos se forjan, y en que parece que el espíritu humano ha creado una polarización indestructible, vulnerable [...] (AZORÍN 1998b, p. 338).

Otro de los temas muy presentes en las estampas que integran Los pueblos $-y$, por extensión, en todo el conjunto de la obra azoriniana- es la reflexión sobre el transcurrir del tiempo. Para Azorín, la historia tiene un sentido cíclico que recuerda en mucho a esa idea nietzscheana del "eterno retorno": todo se repite una y otra vez en la existencia de esos individuos que viven su propia y lenta "intrahistoria", al margen del correr de esa otra "historia oficial" en la que todo se desarrolla muy rápido. Son esos fragmentos de vida que la historia no ha retratado los que más curiosidad le suscitan: "los intersticios del tiempo, los espacios vacíos, esto que no puede ser materia de la historia, porque no ocurre nada, y que, sin embargo, es la esencia de la vida, lo principal de las cosas, han quedado suprimidos, ocultos" (AZORÍN 2012, p. 95). En ese sentido, y salvando las distancias, se puede decir que Azorín tiene una concepción braudeliana de la historia. Y me explico. En el célebre ensayo en el que acuñó el concepto de longue durée, el historiador francés Fernand Braudel denunciaba que la "historia tradicional, atenta al tiempo breve, al individuo y al acontecimiento", nos había habituado a un relato histórico "precipitado, dramático, de corto aliento"; frente a esta historia episódica o de los acontecimientos (histoire événementielle), el por entonces director de la revista Annales proponía "una historia de aliento mucho más sostenido", "una historia de larga, incluso de muy larga, duración" que se fijara en los procesos históricos de amplitud secular (BRAUDEL 1995, p. 64). Azorín no escribe sobre esos largos procesos a los que se refiere Braudel; escribe sobre los pueblos españoles y sobre esos labriegos y herreros que viven al margen de la historia, pero lo hace poniendo un especial énfasis en la continuidad de la historia de España y en cómo esa continuidad se manifiesta 
en la aparente inmovilidad de esas existencias insignificantes que permanecen ajenas a los grandes sucesos de la historia. En el capítulo "Un hidalgo: las raíces de España", el escritor reconstruye la vida de un hidalgo del siglo XVI, personaje del Lazarillo de Tormes, y reflexiona sobre los valores que han caracterizado a España y que se han mantenido a lo largo de esa historia de gran recorrido: "ésta es la grandeza española: la simplicidad, la fortaleza, el sufrimiento largo y silencioso bajo serenas apariencias; ésta es una de las raíces de la patria que ya se van secando" (AZORÍN 1998b, p. 372).

En definitiva, y como vemos en el texto que lleva por título "En Urberuaga" (una crónica de la visita de Azorín al balneario del pueblo guipuzcoano de Cestona), lo que evidencia el conjunto de esas escenas que componen Los pueblos es la atracción estética y sentimental que siente Azorín hacia lo provinciano:

Y de cuando en cuando, en el silencio, oís una tos breve, seca, o una larga, pertinaz. Y sentís que hay algo en este ambiente de íntima y profundamente provinciano: por el enredijo de salas y pasillos con pisos desnivelados, por la simplicidad del moblaje, por los alterones y honduras de las camas, por la llaneza e ingenuidad de la servidumbre, por el prosaísmo castizo de la cocina [...] Mas vosotros, como yo, estáis en un momento en que gustáis de todas estas cosas tan españolas. Dentro de poco, cuando llevéis una hora más en el hotel, vuestro gusto va a ser plenamente satisfecho. Porque os percataréis de que el ambiente que respiráis, no solo es hondamente provinciano, sino que, por una concatenación lógica y necesaria, está también saturado de un romanticismo soñador y melancólico (AZORÍN 1998b, p. 363-364).

La trascendencia de Los pueblos en la evolución estética de su obra fue reconocida por el propio Azorín en un artículo elocuentemente titulado "Confesión de un autor" en el que explicó a los lectores de España (el texto fue publicado con posterioridad a la aparición de la primera edición de Los pueblos y luego fue incorporado como un capítulo más) qué mensaje había querido trasmitir con aquella obra miscelánea. En el párrafo central de esa confesión, que constituye, al decir de Miguel Ángel Lozano Marco, todo "un verdadero ensayo de estética de tal alcance que viene a ser una especie de manifiesto - un original manifiestodel «nuevo arte» logrado en ese libro" (LOZANO MARCO 1998, p. 38), Azorín sintetizaba las claves de ese principio rector - la búsqueda del alma de las cosas en los pequeños hechos de la vida cotidiana- que guiaría en adelante su creación como artista:

¿Por qué tratáis vosotros, hombres superiores, con un desvío benévolo, compasivo, a don Pedro, a don Juan, a don Fernando, a don Rafael, a todos los que viven en estos pequeños pueblos? ¿Por qué escucháis sonriendo, con una sonrisa interior, mayestática, lo que os dicen doña Isabel, doña Juana, doña Margarita, doña Asunción, y doña Amalia? Todo tiene su valor estético y psicológico; los conciertos diminutos de las cosas son tan interesantes para el psicólogo y para el artista como las grandes síntesis universales. Hay una nueva belleza, un nuevo arte en lo pequeño, en los detalles insignificantes, en lo ordinario, en lo prosaico; los tópicos abstractos y épicos que hasta ahora los poetas han llevado y han traído ya no nos dicen nada; ya no se puede hablar con enfáticas generalidades del campo, de la Naturaleza, del amor, de los hombres; necesitamos 
hechos microscópicos que sean reveladores de la vida y que, ensamblados armónicamente, con simplicidad, con claridad, nos muestren la fuerza misteriosa del Universo, esta fuerza eterna, profunda, que se halla lo mismo en las populosas ciudades y en las Asambleas donde se deciden los destinos de los pueblos que en las ciudades obscuras y en las tertulias de un Casino modesto donde D. Joaquín nos cuenta su prosaico paseo de esta tarde (AZORÍN 1998, p. 1609-1610).

Pero Los pueblos no solo es una obra fundamental desde el punto de vista de su renovadora propuesta estética. Estos ensayos sobre la vida provinciana -y en general la obra de Azorín- ofrecen otra posible interpretación no contemplada hasta la fecha por la crítica. Me refiero, por supuesto, a la lectura que se puede hacer desde la perspectiva de ese historiador de España que puede aprender en Azorín una lección valiosa: la de que las "vidas opacas" de esas clases subalternas también forman parte de la historia y merecen por ello nuestra atención. Aunque la suya sea una "historia menuda" de España, es una historia necesaria que, además, se debe hacer "con el mismo rigor con que se hace la grande" (AZORÍN 2012, p. 212).

\section{Azorín como historiador; Azorín para historiadores}

En un capítulo de su libro de recuerdos Madrid, Azorín decía haber pertenecido a una generación de intelectuales y escritores que compartieron su interés común por el conocimiento de la historia de España:

La Historia nos tenía captados. Nos diéramos de ello cuenta o no nos diéramos. Para los resultados finales ha sido lo mismo. Baroja ha escrito una extensa historia de la España contemporánea. Maeztu acopiaba quizás entonces los hilos invisibles con que había de tejer su teoría histórica de la hispanidad. En cuanto a mí, el tiempo en concreto, es decir, la Historia, me ha servido de trampolín para saltar al tiempo en abstracto. La generación de 1898 es una generación historicista (AZORÍN 1952, p. 58).

En el caso concreto de la obra que me he propuesto analizar aquí, esa mirada hacia atrás no es un relato ortodoxo sobre la historia de España; Los pueblos es más bien una obra miscelánea en la que conviven géneros y se combinan registros que sirven al autor para "pintar" esos pequeños cuadros de la vida provinciana española. Sin embargo, parece una obra acabada, un todo coherente que tiene en la sensibilidad de su autor por esa "historia menuda" el elemento cohesionador que impregna el conjunto de ese "aire de familia" azoriniano que lo hace reconocible. Desde esa perspectiva, Los pueblos es quizá el libro que ejemplifica mejor la teoría orteguiana según la cual, "Azorín es todo lo contrario de un filósofo de la historia: es un sensitivo de la historia"; mientras que el primero "se complace en ordenar, como en procesión o cabalgata, las variaciones de la humana existencia, el siglo opulento y glorioso tras el humilde y sin destellos", el arte de Azorín -insiste Ortega- "consiste en revivir esa sensibilidad básica del hombre a través de los tiempos" (ORTEGA Y GASSET 2004, p. 296-297).

Esta sensibilidad de Azorín hacia las "vidas opacas" no es incompatible con la atracción que nuestro autor sintió por los grandes personajes de la historia. 
De hecho, y en honor a la verdad, hay que decir que el escritor también dedicó algunos textos a recordar - para ensalzarlos o para criticarlos- distintos períodos de la historia de España (la época de los Trastámaras, el reinado de los Reyes Católicos, la rendición de Granada, etc.) y a trazar retratos - unas veces más hagiográficos, otras más neutrales- de algunos personajes históricos por los que sentía interés y, en algún caso, cierta simpatía (Fernando el Católico, Carlos I, Felipe II, José Antonio Primo de Rivera). ${ }^{2}$ A mi juicio, no son intereses contradictorios ni necesariamente excluyentes, pues una cosa es querer conocer bien - como lo quería Azorín - el pasado de su país y otra muy distinta es ser consciente de que la historia no acaba ahí, en ese relato canónico, sino de que hay otra realidad oculta de la que no se han ocupado los historiadores.

Seguramente, esa dualidad en los gustos guarda relación con dos aspectos importantes: en primer lugar, la evolución ideológica de un Azorín que, como es sabido, abandonó muy pronto su anarquismo de juventud para adoptar ya para el resto de su vida - una postura inequívocamente conservadora; en segundo lugar, tiene que ver $-y$ no en menor grado- con el contexto cultural desde el cual se juzga al autor y con la intentio lectoris con la que se han interpretado sus obras.

Como ha explicado Francisco José Martín, durante la posguerra franquista nuestro autor fue "víctima" - como otros miembros de su generación- de un intento de apropiación por parte de una serie de intelectuales falangistas encabezados por Pedro Laín Entralgo y su ensayo La generación del 98 (1945)— que trataron de aprovechar el prestigio alcanzado por esos escritores para ponerlo al servicio de la causa franquista. En el caso particular de Azorín, esa maniobra consistió básicamente en silenciar su etapa juvenil de actividad más crítica con la sociedad y su labor política e intelectual en favor de la modernización de España, con el objeto deliberado de:

[...] levantar la imagen del "escritor puro", del estilista por antonomasia, preocupado por la perfección de la página, por el fluir temporal y por la evocación de España, índice todo ello, a la postre, de un patriotismo rancio, pero muy eficaz, sobre todo a la hora de mostrar su aval al nuevo régimen (MARTIN 2007, p. 15).

Lo que he querido proponer aquí es una lectura de Los pueblos que fijara la mirada en esa faceta menos conocida de la obra de Azorín como historiador de lo menudo. En resumen, he pretendido Ilamar la atención sobre la potencialidad de la obra azoriniana como objeto de estudio y reflexión para los historiadores, especialmente para aquellos que todavía se empeñan en subordinar el interés de ciertas metodologías - microhistoria, historia desde abajo e historia local- en favor de la historia política y socioeconómica tradicional, atenta a las grandes estructuras y a los personajes más relevantes. Aunque no figure en la historia de España que se cuenta en los libros y se enseña en la universidades, nos viene a decir el escritor 
alicantino con su mensaje que la vida de cualquier individuo es digna de ser tenida en cuenta como materia histórica: desde la de Felipe II o Carlos V, hasta la del más paupérrimo labriego de la Mancha quijotesca o de los pueblos de esa Andalucía trágica que él mismo describió. A mi juicio, esa es la principal aportación de Azorín al concepto de la historia que se tenía en España y esta es la necesaria y oportuna pregunta que sus reflexiones nos dejan sobre la mesa:

¿Cómo explicaréis mejor las vicisitudes de España: leyendo los libros de historia o charlando con los tipos de los pueblos, los tipos más castizos, los menos internacionalizados? Todo es necesario. Pero la charla y el trato de estos hombres nos ahorra muchas horas de lectura y nos aclara problemas que parecían inextricables. D. Manuel, D. Pedro, D. Leandro [...], cada uno lleva su marcha y es un pedacito de historia patria. Tratemos de comprenderlos. $Y$ no afectemos desdén, superioridad respecto a hombres que, tal vez sin erudición, ni sin haber dejado su casa ni una hora, pudieran tener de las cosas una visión más exacta que la nuestra de hombres eruditos, cultos y mundanos (AZORÍN 1917, p. 83).

\section{Referencias bibliográficas}

AZORÍN. Páginas escogidas. Madrid: Editorial Calleja, 1917.

. Madrid. Buenos Aires: Editorial Losada, 1952 [1941].

. Una hora de España (entre 1560 y 1570). Madrid: Espasa Calpe, 1957 [1924].

. Las confesiones de un pequeño filósofo. Madrid: Espasa Calpe, 1990 [1904].

- La muerte de un amigo: Sarrió. In: LOZANO MARCO, Miguel Ángel (coord.). Obras escogidas. Madrid: Espasa Calpe, 1998. V. II.

. Los pueblos. In: LOZANO MARCO, Miguel Ángel (coord.), Obras escogidas. Madrid: Espasa Calpe, 1998b. V. II.

. La historia. In: FUSTER GARCÍA, Francisco (ed.). ¿Qué es la historia?

Reflexiones sobre el oficio de historiador. Madrid: Fórcola, 2012.

BRAUDEL, Fernand. La larga duración. In: . La historia y las ciencias

sociales. Madrid, Alianza, 1995 [1958].

GINZBURG, Carlo. El queso y los gusanos: el cosmos de un molinero del siglo XVI. Barcelona: Península, 2011 [1976].

- Ninguna isla es una isla: cuatro visiones de la literatura inglesa desde una perspectiva mundial. Villahermosa: Universidad Autónoma Juárez Tabasco, 2003 [2000].

Historia nocturna: las raíces antropológicas del relato. Barcelona: Península, 2003 [1989].

JIMÉNEZ MADRID, Ramón. Introducción. In: AZORÍN. Los pueblos (ensayos sobre la vida provinciana). Madrid: Biblioteca Nueva, 2002. 
LOZANO MARCO, Miguel Ángel. Introducción: los ensayos de Azorín. In: LOZANO MARCO, Miguel Ángel (coord.). Obras escogidas. Madrid: Espasa Calpe, 1998. V. II.

MARAVALL, José Antonio. Azorín: idea y sentido de la microhistoria. Cuadernos Hispanoamericanos, n. 226-227, p. 28-77, 1968.

MARTÍN, Francisco José. Introducción. In: AZORÍN. El político. Madrid: Biblioteca Nueva, 2007.

ORTEGA Y GASSET, José. Azorín o primores de lo vulgar. In: El Espectador II, Obras Completas. Madrid: Taurus/ Fundación Ortega y Gasset, 2004. V. II.

SERNA, Justo; PONS, Anaclet. Cómo se escribe la microhistoria: ensayo sobre Carlo Ginzburg. Madrid: Cátedra/PUV, 2000.

VALVERDE, José María. Introducción crítica. In: AZORÍN. Los pueblos, La Andalucía trágica y otros artículos (1904-1905). Madrid: Castalia, 1974. 